Research Article

\title{
Novel Model for Manoeuvrability of Ships Advancing in Landslide-Generated Tsunamis
}

\author{
Peiyin Yuan (D), ${ }^{1}$ Pingyi Wang, ${ }^{2}$ and Yu Zhao ${ }^{2,3}$ \\ ${ }^{1}$ College of Shipping and Naval Architecture, Chongqing Jiaotong University, Chongqing 400074, China \\ ${ }^{2}$ Collegeh of River and Ocean Engineering, Chongqing Jiaotong University, Chongqing 400074, China \\ ${ }^{3}$ College of Architecture and Urban Planning, Chongqing Jiaotong University, Chongqing 400074, China
}

Correspondence should be addressed to Peiyin Yuan; yuan_pei_yin@163.com

Received 1 June 2020; Revised 29 July 2020; Accepted 14 August 2020; Published 28 August 2020

Academic Editor: Chiara Bedon

Copyright (c) 2020 Peiyin Yuan et al. This is an open access article distributed under the Creative Commons Attribution License, which permits unrestricted use, distribution, and reproduction in any medium, provided the original work is properly cited.

\begin{abstract}
The rock and soil on the shore of the bank are unsteady and slide in a poor environment, affecting the water body in the river channel and forming landslide-generated tsunamis. This directly impacts the navigation of vessels in the river. In this study, the river course and sailing ships in the Wanzhou section of the Three Gorges Reservoir area were taken as the research objects. Through a physical model test with a large scale ratio, the variation of the water level at the monitoring points in the channel was determined, and the variation law of the water level in the whole channel was derived and converted into a prototype through the scale ratio. A model of the ship's manoeuvring motion was established, and the ship's manoeuvring motion characteristics in still water were verified. The correlations between the maximum roll angle and the navigation position, sailing speed, and rudder angle were investigated in detail. A safety risk response theory of navigation in the area of landslide-generated tsunamis was proposed, and a scientific basis was provided for the safe navigation of ships in the Three Gorges Reservoir area.
\end{abstract}

\section{Introduction}

Under the influence of strong earthquakes, heavy rain, and changes in the reservoir water level, the rock and soil of reservoirs are prone to landslides, and the movement of landslides into river channels at high speeds causes landslide-generated tsunamis, which propagate along the upper and lower reaches of the river, affecting hydraulic structures, passing ships, and residents of coastal areas.

Scholars have used theoretical analyses, model test methods, and numerical simulation methods to study the propagation of landslide-generated tsunamis and the characteristics of ship manoeuvring motions. To study landslide-generated tsunamis via model tests, experts have conducted two-dimensional (2D) test methods. Fritz [1] performed preliminary experiments involving a falling block and a wedge block. The wave generation between the two methods differs because the sliding wedge does not produce the reverse separation vortex. Watts et al. [2] performed experiments on submarine landslides using a semiellipsoid and compared the experimental results with the depth-averaged nonlinear shallow water wave equations. Experts have also used three-dimensional (3D) testing methods. Panizzo et al. [3] performed 3D block slide experiments in a $6 \mathrm{~m}$-wide, $12 \mathrm{~m}$-long, and $0.8 \mathrm{~m}$-deep wave basin. The rectangular block slide was released at the end of the basin adjacent to the side wall, assuming the symmetry of the wave propagation. Di Risio et al. [4] used half an ellipsoid-shaped block to model a landslide in a $5.5 \mathrm{~m}$-wide, $1.8 \mathrm{~m}$-deep, and $10.8 \mathrm{~m}$-long wave basin. Experts have compared the characteristics of landslide-generated tsunami propagation in 2D and 3D tests. Heller et al. [5], Bruggemann [6], and Heller and Spinneken [7] obtained the initial high-speed calculation formula and the law of landslide-generated tsunamis.

The uncertainty and propagation characteristics of landslide-generated tsunamis are difficult to measure, and 
scholars have used different numerical methods to study the characteristics of landslide-generated tsunamis. YavariRamshe and Ataie-Ashtiani [8] presented a new landslidegenerated model based on incompressible Euler equations. A two-layer model was developed that included a layer of granular-type flow beneath a layer of inviscid flow. AtaieAshtiani and Yavari-Ramshe [9] estimated the impact of landslide-generated waves using a 2D fourth-order Boussinesq-type numerical model. Ruffini et al. [10] focused on numerical landslide tsunami propagation in the far field to quantify the effect of the water-body geometry. Kelfoun et al. [11] used a new two-fluid (seawater and landslide) numerical model to estimate the wave amplitudes and the propagation of tsunamis associated with landslide events on Reunion Island. Farhadi [12] performed a numerical simulation of the gravity currents of non-Newtonian fluids via the incompressible smoothed particle hydrodynamics approach. Cecioni and Bellotti [13] presented a depth-integrated numerical model for the simulation of the generation and propagation of tsunamis due to submerged landslides.

The movement of ships on waves has been investigated via numerical simulations and model tests. Hirdaris et al. [14] reviewed some of the recent advances in the assessment of loads for ships and offshore structures with the aim of presenting the overall technological landscape for further investigation, validation, and implementation by the academic and industrial communities. Sasa et al. [15] performed a numerical simulation of ship motions by using a coastal network wave database. Some experts focused on the movement characteristics of the ship in its six degrees of freedom. Kianejad et al. [16] performed numerical and experimental simulations to examine the effects of different wave heights and wave frequencies on the ship motion characteristics. Piscopo et al. [17] examined the heave and pitch motion time histories via a time-domain simulation, according to theoretical wave spectra. Scholars have also studied the manipulation of ships. Seo and Kim [18] performed a numerical analysis of the ship manoeuvring performance in the presence of incident waves and the resultant ship motion responses. Szlapczynski et al. [19] used a model of the ship dynamics to assess the time and distance necessary for a manoeuvre to avoid domain violations. Lee and Kim [20] considered the effects of the steady flow approximation in the analysis of ship manoeuvring in waves. Owing to the strong nonlinear effect of landslide surges, the traditional linear potential flow theory is not accurate. Scholars such as Yuan et al. [21, 22] employed engineering examples and the orthogonal model test method to study the navigational safety of ships in landslide-generated tsunami waters.

In summary, scholars have performed considerable research on the propagation characteristics of landslide-generated tsunamis, the laws of ship movement, and the ship manoeuvres via various methods, such as theoretical analysis, numerical simulation, field observation, and indoor experiments. However, few studies have been performed on the direct development of landslide-generated tsunamis and ship motion, and there has been even less theoretical research on the effect of landslidegenerated tsunamis on the ship. Therefore, according to the four-degree-of-freedom motion equation of ships and the characteristics of landslide-generated tsunami propagation, this paper presents simulation procedures for studying the effects of landslide-generated tsunamis on ship manoeuvring, along with scientific suggestions and theoretical support for the navigational safety of ships in landslide-generated tsunami waters.

\section{Mathematical Model of Ship Manipulation Motion}

2.1. Coordinate Systems. To facilitate the study of the movement of the hull in the water, two right-handed coordinate systems are selected. The first is the inertial coordinate system fixed to the Earth's surface $\left(o_{0}-x_{0} y_{0} z_{0}\right)$ and $z_{0}$. The ship's transverse velocity along the $Y$-axis is denoted as $v$, the forward angular velocity around the $z$-axis is denoted as $r$, and the roll angular velocity around the $X$-axis is denoted as $p$. The external force and external torque suffered by the ship in the manoeuvring motion coordinate system can be expressed in terms of the longitudinal force $x$ along the $X$-axis, transverse force $y$ along the $Y$-axis, foreword moment $N$ around the $z$ axis, and roll moment $K$ around the $X$-axis.

The main characteristic of the MMG model is applied to the hydrodynamic force and moment on the ship in accordance with the physical meaning and is decomposed into the work on the naked hull, the propeller open water, and the hydrodynamic force and moment on the open-water rudder, as well as the mutual interference between the hydrodynamic force and moment. The MMG model is based on a deep and extensive experimental study together with theoretical analysis and is a popular international mathematical model for ship motion. It has high reliability (Figures 1 and 2).

Relationship between the physical quantities in the process of ship manipulation:

$$
\left\{\begin{array}{l}
\dot{x}_{\mathrm{GO}}=\mu \cos \phi-\nu \sin \phi, \\
\dot{y}_{\mathrm{GO}}=\mu \sin \phi+\nu \cos \phi, \\
\dot{\phi}=r, \\
\dot{\varphi}=p,
\end{array}\right.
$$

where $\phi$ represents the direction angle and $\varphi$ represents the roll angle.

2.2. Equation of Ship Manipulation Motion. The ship's movement in the water is rigid-body movement. The mass is denoted as $m$. According to the law of rigid weight heart movement, Newton's law, and the momentum theorem, the following can be obtained:

$$
\left\{\begin{array}{l}
m \ddot{x}_{\mathrm{GO}}=X_{0}, \\
m \ddot{y}_{G O}=Y_{0}, \\
I_{z z} \ddot{\phi}=N_{0}, \\
I_{x x} \ddot{\varphi}=K_{0},
\end{array}\right.
$$

where $I_{z z}$ represents the moment of inertia of the hull against the $X$-axis and $I_{x x}$ represents the moment of inertia of the hull against the $Y$-axis. The derivatives of both sides of equation (2) can be obtained as follows: 


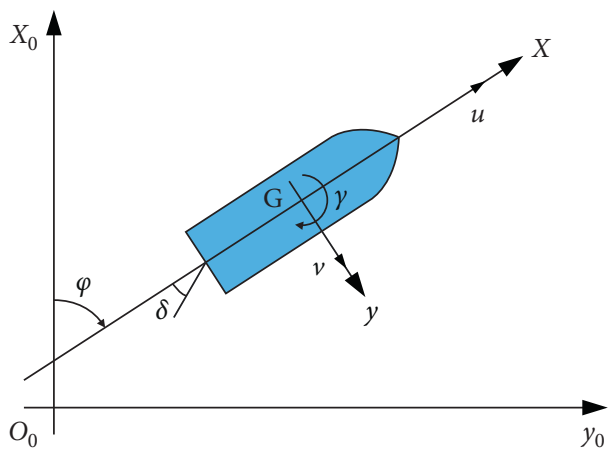

Figure 1: Coordinate systems.

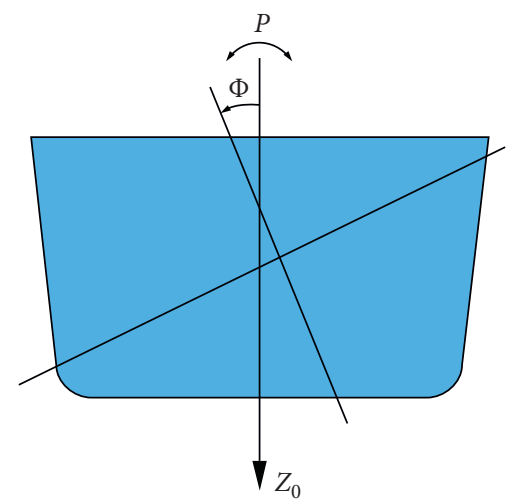

Figure 2: State of ship motion.

$$
\left\{\begin{array}{l}
\ddot{x}_{\mathrm{GO}}=\dot{\mu} \cos \phi-\dot{v} \sin \phi-(\mu \sin \phi+\nu \cos \dot{\phi}) \dot{\phi}, \\
y_{\mathrm{GO}}=\dot{\mu} \sin \phi+\dot{v} \cos \phi+(\mu \cos \phi-\nu \sin \dot{\phi}) \dot{\phi}, \\
\ddot{\phi}=\dot{r} \\
\ddot{\varphi}=\dot{p} .
\end{array}\right.
$$
yields

Substituting equations (4) and (1) into equation (3)

$$
\left\{\begin{array}{l}
X=m(\dot{\mu}-v r), \\
Y=m(\dot{\nu}+\mu r), \\
N=I_{z z} \dot{r}, \\
K=I_{z z} \dot{p} .
\end{array}\right.
$$

According to the MMG model, a mathematical model of the ship's movement in four degrees of freedom can be obtained by dividing the external force and external torque of the hull by the bare ship strength, propeller force, and rudder force:

$$
\left\{\begin{array}{l}
X=m(\dot{\mu}-v r)=X_{\mathrm{HO}}+X_{P}+X_{R}, \\
Y=m(\dot{v}+\mu r)=Y_{\mathrm{HO}}+Y_{P}+Y_{R}, \\
N=I_{z z} \dot{r}=N_{\mathrm{HO}}+N_{P}+N_{R}, \\
K=I_{x x} \dot{p}=K_{\mathrm{HO}}+K_{P}+K_{R},
\end{array}\right.
$$

where the subscripts $\mathrm{H} 0, P$, and $R$ correspond to the hull, propeller, and rudder, respectively. If the effects of wind and waves are considered, the wind interference and wave interference are added to the various backs.

2.3. Model of Fluid Dynamic Stream and Torque Calculation for Bare Hull. The fluid force and torque on the bare hull can be divided into two components: the inertial fluid dynamics caused by inertia and the viscous fluid dynamics caused by viscosity. In this study, the interaction between the two fluid dynamics is not considered in calculating the forces and torques. The fluid dynamics $\mathrm{HO}$ on the bare hull can be expressed as follows:

$$
\left\{\begin{array}{l}
X_{\mathrm{HO}}=X_{1}+X_{H}, \\
Y_{\mathrm{HO}}=Y_{1}+Y_{H}, \\
N_{\mathrm{HO}}=N_{1}+N_{H}, \\
K_{\mathrm{HO}}=K_{1}+K_{H},
\end{array}\right.
$$


where the subscripts $I$ and $H$ correspond to the inertial and viscous fluid dynamics, respectively.

2.4. Model of Propeller and Calculation of Host Characteristics. In this study, the ship's main speed and vertical speed are considered to be $>0$ in the course of navigation, and the propeller thrust and torque model is established as follows:

$$
\left\{\begin{array}{l}
X_{P}=\left(1-t_{p}\right) T, \\
T=\rho n^{2} D_{P}^{4} k_{T}\left(J_{P}\right), \\
Q_{P}=\rho n^{2} D_{P}^{5} k_{Q}\left(J_{P}\right),
\end{array}\right.
$$

where $t_{P}$ represents the thrust deduction factor, $T$ represents the propeller thrust, $\rho$ represents the fluid density, $n$ represents the propeller revolution, $D_{P}$ represents the propeller diameter, $k_{T}\left(J_{P}\right)$ represents the propeller thrust coefficient, and $k_{Q}\left(J_{P}\right)$ represents the propeller torque coefficient.

In this study, the thrust coefficient and the torque coefficient are both functions of the propeller's advance speed coefficient, which can be expressed as follows:

$$
\left\{\begin{array}{l}
k_{T}=a_{0}+a_{1} J_{P}+a_{2} J_{P}^{2}, \\
k_{Q}=b_{0}+b_{1} J_{P}+b_{2} J_{P}^{2},
\end{array}\right.
$$

where $a_{0}, a_{1}$, and $a_{2}$ and $b_{0}, b_{1}$, and $b_{2}$ are the regression coefficients for the open-water characteristics of the propeller.

\subsection{Fluid Dynamics and Torque Calculation Model of Rudder.} For rotational motion, the ship is mainly steered using the rudder. The calculation model for the rudder is as follows:

$$
\left\{\begin{array}{l}
X_{R}=\left(1-t_{R}\right) F_{N} \sin \delta, \\
Y_{R}=\left(1+a_{H}\right) F_{N} \cos \delta, \\
N_{R}=\left(x_{R}+a_{H} x_{H}\right) F_{N} \cos \delta, \\
K_{R}=-\left(1+a_{H}\right) z_{R} F_{N} \cos \delta,
\end{array}\right.
$$

where $F_{N}$ represents the positive pressure perpendicular to the rudder surface, $t_{R}$ represents the rudder force derate factor, $\delta$ represents the rudder angle, $a_{H}$ represents the steering-induced lateral force correction factor for the hull, $x_{H}$ represents the distance between the point of steering to induce the hull lateral force and the centre of gravity, $x_{R}$ represents the longitudinal distance from the centre of the rudder to the centre of gravity of the hull, and $z_{R}$ represents the vertical distance from the centre of the rudder to the centre of gravity of the hull.

The formula for calculating the positive pressure of the rudder is as follows:

$$
\left\{\begin{array}{l}
F_{N}=-\frac{1}{2} \rho A_{R} f_{\alpha} U_{R}^{2} \sin \alpha_{R}^{2}, \\
f_{\alpha}=\frac{6.13 \lambda}{2.25+\lambda},
\end{array}\right.
$$

where $A_{R}$ represents the rudder area, $U_{R}$ represents the effective incoming velocity, $\alpha_{R}$ represents the effective angle of the incoming flow, and $\lambda$ represents the thickness ratio of the rudder.

\section{Model Test}

Because of the large-scale landslide surge occurred in the nature, it is difficult to capture the landslide surge of original data. Through the present research of the Three Gorges Reservoir area river by the model test, the model scale is determined according to the Froude number. In this study, the physical model mainly includes the chute, carriage, river, landslide, ultrasonic wave acquisition analyser, etc. Through a large-scale model test, the spread characteristic of the landslide surge is examined.

3.1. Chute. The chutes are made of high-strength steel. They have overall lengths of 2 and $0.6 \mathrm{~m}$, and their widths can be adjusted to $0.5,1.0$, and $1.5 \mathrm{~m}$. The chutes are equipped with a side board, floor, internal demand placed landslide, the chute through ascension device fixed on the sliding shelves, the chute and chute plate inside have been burnished before the test in order to total frictional resistance of equal, chute and carriage, as shown in Figure 3.

3.2. Channel Model. The length of the straight section is $28 \mathrm{~m}$, the centre line radius of the bending section is $7 \mathrm{~m}$, the length of the straight section of the bending section is $13 \mathrm{~m}$, the width of the upper edge of the river is $8 \mathrm{~m}$, and the river section has the shape of an inverted trapezoid. The main construction process of the river is as follows: (1) by the method of model of generalised channel model; (2) cross section design and processing in accordance with the actual survey data; (3) the channel model of each $3 \mathrm{D}$ layout (ensuring the accuracy of the data for every cross section); (4) the lofting process of the boards (ensuring the accuracy of each section after conversion in accordance with the original data); (5) decomposition of the whole river (at the bottom) into a linear area, a landslide area, and a river bend area for generalised processing; (6) casting of the river and building based on the model after the lofting; (7) waterproofing the constructed model to prevent leakage and ensure its effectiveness, as shown in Figure 4 .

3.3. Measurement Methods. The measuring instrument was a self-developed ultrasonic wave acquisition analyser, which can determine the maximum wave height, maximum period, meaningful wave height, and meaningful period at different monitoring points. In the test, the acquisition time of the equipment was $50 \mathrm{~s}$, and the acquisition frequency was $50 \mathrm{~Hz}$. Instruments were arranged in the river to measure the swell characteristics. The instruments were tested and had good adaptability and accuracy. The ultrasonic wave analyser had 16 channels. To facilitate the sorting of the test data, each channel corresponded to a 


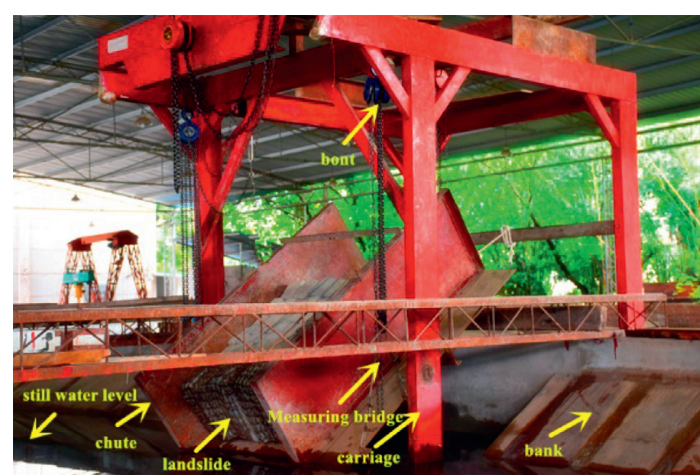

FIgURE 3: Chute and carriage.

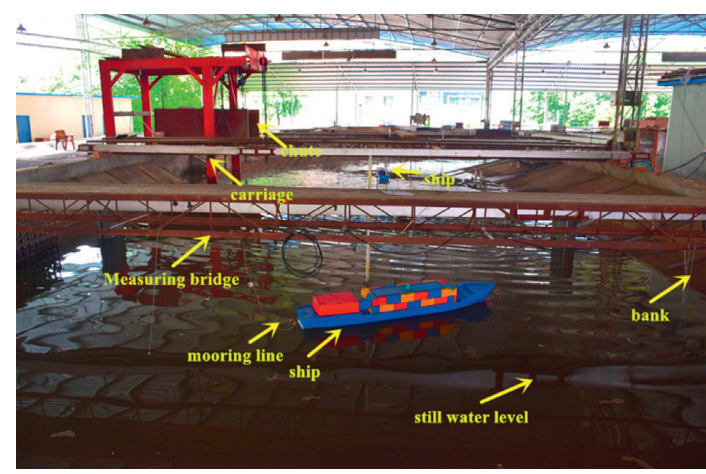

Figure 4: Solid model diagram of the channel.

measurement point. Channel 8 was a ground wire placed at the bottom of the channel model. In the test, a $1 \mathrm{M} \mathrm{ul-}$ trasonic probe with an accuracy of $<0.1 \mathrm{~mm}$ was used to calibrate the sensor on an electric displacement platform of $5 \mu \mathrm{m}$. Additionally, the ultrasonic wave meter was installed on the measuring bridge. The most generous slope was selected for the sliding down the chute, and the ultrasonic wave meter was placed $30 \mathrm{~cm}$ below the water surface according to the maximum measured value of the first wave height of the landslide surge. The measuring instrument was calibrated.

3.4. Verification of Results. After the sliding of the slider along the chute, the changes of the liquid level at different times were compared with the calculation results of Heinrich [23]. As shown in Figure 5, the test results were consistent with Heinrich's calculations.

The calculated results of this experiment were slightly smaller than those of Heinrich, mainly because the landslide in this paper was 3D and scattered, and the collision of the landslide during the sliding process was accompanied by energy dissipation. The second is the inverted trapezoid of the test channel. The landslide surge is accompanied by reflection and superposition in the process of propagation, which affect the water level at the monitoring point.

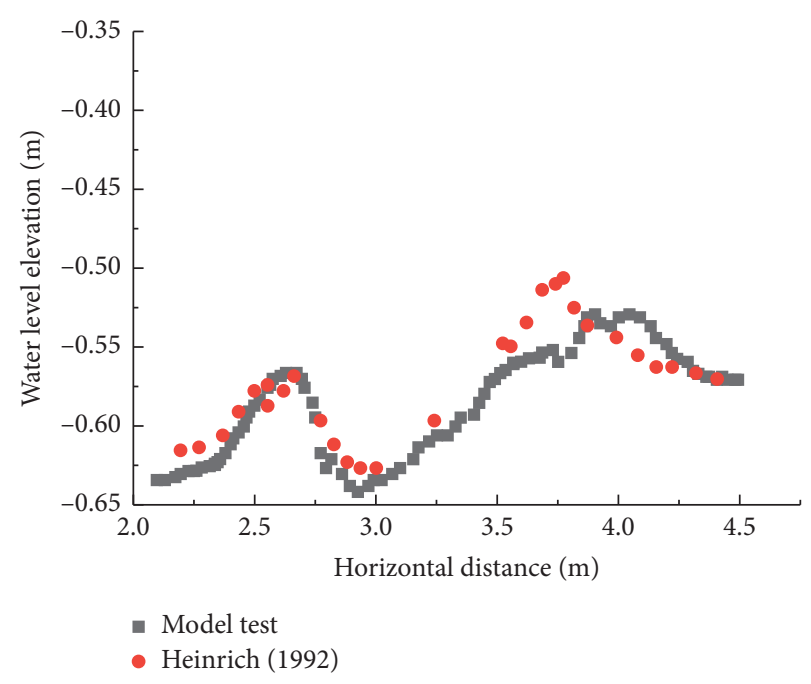

FIgURE 5: Comparison between the model test results and the calculations of Heinrich for $t=1.5 \mathrm{~s}$.

\section{Simulation of Ship Manipulation Motion in Still Water}

4.1. Roll Analysis of Operating Conditions for Propeller Revolution. In this study, a Yangtze River cruise ship was taken as the research object. A roll test of the ship was simulated, and the results were compared with the experimental data. The ship's manoeuvring performance was predicted, and the mathematical model for the ship manoeuvring was verified. The main parameters of the ship's main scale and rudder and oars are presented in Table 1.

Under hydrostatic conditions, the initial state of the pilot ship's roll test is presented in Table 2.

By establishing a model of the ship-operated motion, the turning circle motion of the ship in still water was analysed. The ship's roll trajectories for different propeller speeds are shown in Figures 6 and 7.

The roll characteristic parameters solved via numerical simulation were compared with the ship test results, and the error was evaluated, as shown in Table 3.

For the ship in static water, the following conclusions can be drawn from the gyration trajectory and characteristic parameters of the ship at different main engine speeds:

(1) The propeller revolution was timed, and the roll ring sizes differed slightly between the port and starboard. This was due to the "zero positive rudder angle"; for the ship in the operating corner of the rudder, the actual rudder did not have an angle of zero but was slightly skewed in a certain direction, leading to a small difference between the port and starboard under the same roll diameter.

(2) The propeller speed was $122 \mathrm{r} / \mathrm{min}$, corresponding to an initial ship speed of $26 \mathrm{~km} / \mathrm{h}$. The rotation characteristic parameters compared to the propeller speed of $154 \mathrm{r} / \mathrm{min}$, corresponding to the initial speed of $32 \mathrm{~km} / \mathrm{h}$. Ship propeller speed increased, the 
TABLE 1: Target ship master scale and main parameters of the rudder and pulp.

\begin{tabular}{lc}
\hline Overall length $L(\mathrm{~m})$ & 141.80 \\
Length on the waterline $L_{w l}(\mathrm{~m})$ & 132.0 \\
Breadth moulded $B(\mathrm{~m})$ & 19.40 \\
Depth moulded $D(\mathrm{~m})$ & 11.40 \\
Designed draft $d(\mathrm{~m})$ & 6.80 \\
Block coefficient $C_{b}$ & 0.821 \\
Prismatic coefficient $C_{P}$ & 0.863 \\
Displacement $\nabla(t)$ & 12000 \\
Area of rudder $A_{R}\left(\mathrm{~m}^{2}\right)$ & 25.15 \\
Rudder height $H_{R}(\mathrm{~m})$ & 6.2 \\
Aspect ratio of rudder $\lambda$ & 1.02 \\
Number of blades $Z$ & 4 \\
Diameter of propeller $D_{P}(\mathrm{~m})$ & 4.8 \\
Screw pitch $P(\mathrm{~m})$ & 3.2 \\
\hline
\end{tabular}

TABLe 2: Initial state of the target ship in a static water turning circle.

\begin{tabular}{lcc}
\hline Order rudder angle $\delta_{E}\left({ }^{\circ}\right)$ & 35.0 & -35.0 \\
Draft $d(\mathrm{~m})$ & 4.40 & 4.40 \\
Distance from midship to centre of buoyancy $x_{B}$ & 0.80 & 0.80 \\
$(\mathrm{~m})$ & 5234.0 & 5234.0 \\
Displacement $\nabla(t)$ & 154 & 122 \\
Engine speed $n(\mathrm{r} / \mathrm{min})$ & 32 & 26 \\
Initial speed $V(\mathrm{~km} / \mathrm{h})$ & 0.0 & 0.0 \\
Initial set rudder angle $\delta\left(^{\circ}\right)$ & 5.6 & 5.6 \\
Height of CG $(\mathrm{m})$ & 6.8 & 6.8 \\
Initial transverse metacentric height $(\mathrm{m})$ & &
\end{tabular}

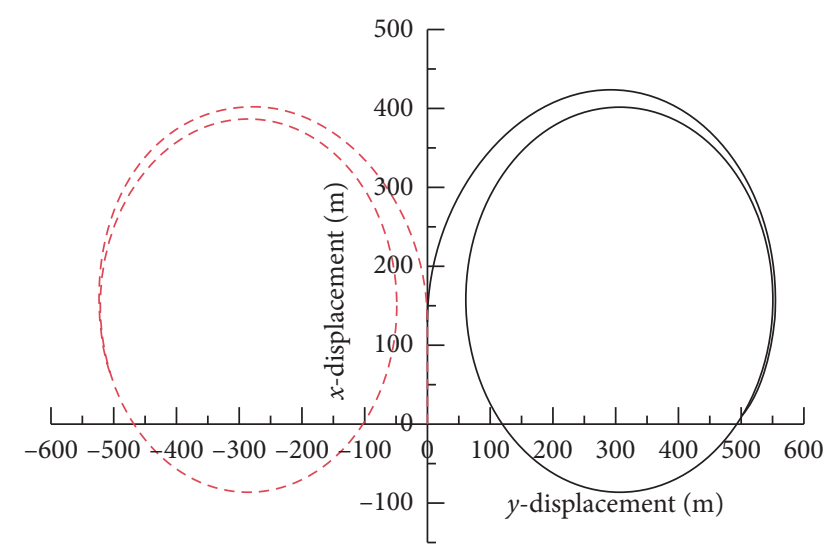

$\begin{array}{ll}\text { - } & \text { Rudder } 35 \text { deg } \\ -- & \text { Rudder }-35 \text { deg }\end{array}$

FIGURE 6: Rotation trajectory for a rudder angle of approximately $35^{\circ}$ (main engine speed of $154 \mathrm{r} / \mathrm{min}$ ).

ship speed increased, but the roll performance was degraded.

(3) The simulation results were compared with the ship test data. The error of each roll characteristic parameter of the ship was within $\pm 20 \%$ and far smaller than $20 \%$, satisfying the precision requirements for engineering applications. Thus, the mathematical

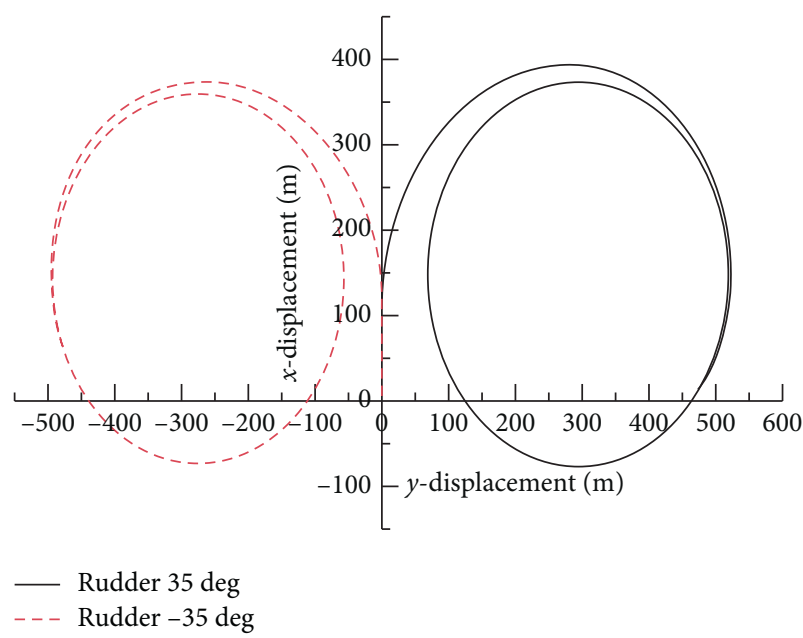

FIGURE 7: Rotation trajectory for a rudder angle of approximately $35^{\circ}$ (main engine speed of $122 \mathrm{r} / \mathrm{min}$ ).

model of ship manipulation motion used in this study is correct and reasonable, and further simulations can be performed using this model.

(4) The simplified manoeuvring motion model of ships in landslide surge waters, such as the hydrodynamic performance of propellers and rudders, may cause errors in the calculation results. However, during ship rotation, the variation trends of various parameters of ship rotation were consistent with the theoretical research results for the ship manoeuvring motion, indicating the reliability and correctness of the mathematical model.

The rolling change curves as the starboard rolls the ship at different propeller speeds are shown in Figure 8. The following observations were made.

(1) The ship's roll process can be divided into three stages. In the initial stage of rotation, the ship tilted towards the inside of the circle and reached the initial angle of rotation owing to the transverse force of the hull and rudder. In the transition stage, it gradually inclined towards the outside of the circle, exceeded the roll angle, and reached the maximum dynamic roll angle. In the steady turning stage, the steady turning angle was stabilised.

(2) When the propeller speed was $154 \mathrm{r} / \mathrm{min}$, the simulation indicated that the initial tilt angle of the roll was $0.74^{\circ}$, the maximum power roll angle was $8.75^{\circ}$, and the roll angle of steady rotation was approximately $2.57^{\circ}$. When the propeller speed was $122 \mathrm{r} / \mathrm{min}$, the maximum power roll cross-roll angle was $5.79^{\circ}$, and the roll angle of steady rotation was approximately $1.62^{\circ}$. While propeller speed affected the initial speed of the ship, the ship roll had a greater impact. When the speed of the main engine increased, the maximum dynamic roll angle of the ship's hydrostatic rotation increased, along with the stable roll angle of the steady rotation stage. 
TABle 3: Ship turning characteristic parameters.

\begin{tabular}{|c|c|c|c|c|c|c|c|}
\hline & \multirow{2}{*}{ Rotary elements } & \multicolumn{2}{|c|}{ Ship test data } & \multicolumn{2}{|c|}{ Simulation results } & \multicolumn{2}{|c|}{ Error $(\%)$} \\
\hline & & $\delta=35^{\circ}$ & $\delta=-35^{\circ}$ & $\delta=35^{\circ}$ & $\delta=-35^{\circ}$ & $\delta=35^{\circ}$ & $\delta=-35^{\circ}$ \\
\hline \multirow{4}{*}{ Engine speed: $154 \mathrm{r} / \mathrm{min}$} & Advance $(\mathrm{m})$ & 430.6 & 413.2 & 419.7 & 398.9 & -2.53 & -3.46 \\
\hline & Transfer (m) & 254.0 & 239.8 & 249.8 & 234.0 & -1.65 & -2.42 \\
\hline & Tactical diameter $(\mathrm{m})$ & 558.2 & 533.3 & 551.0 & 522.8 & -1.29 & -1.97 \\
\hline & Steady turning diameter $(\mathrm{m})$ & 470.6 & 458.4 & 487.8 & 472.7 & +3.65 & +3.12 \\
\hline \multirow{4}{*}{ Engine speed: $122 \mathrm{r} / \mathrm{min}$} & Advance $(\mathrm{m})$ & 412.2 & 400.3 & 391.1 & 372.4 & -5.12 & -6.97 \\
\hline & Transfer (m) & 226.8 & 211.5 & 234.0 & 220.6 & +3.17 & +4.30 \\
\hline & Tactical diameter $(\mathrm{m})$ & 518.7 & 489.2 & 519.9 & 492.4 & +0.23 & +0.65 \\
\hline & Steady turning diameter $(\mathrm{m})$ & 453.9 & 434.6 & 447.3 & 433.6 & -1.45 & -0.23 \\
\hline
\end{tabular}

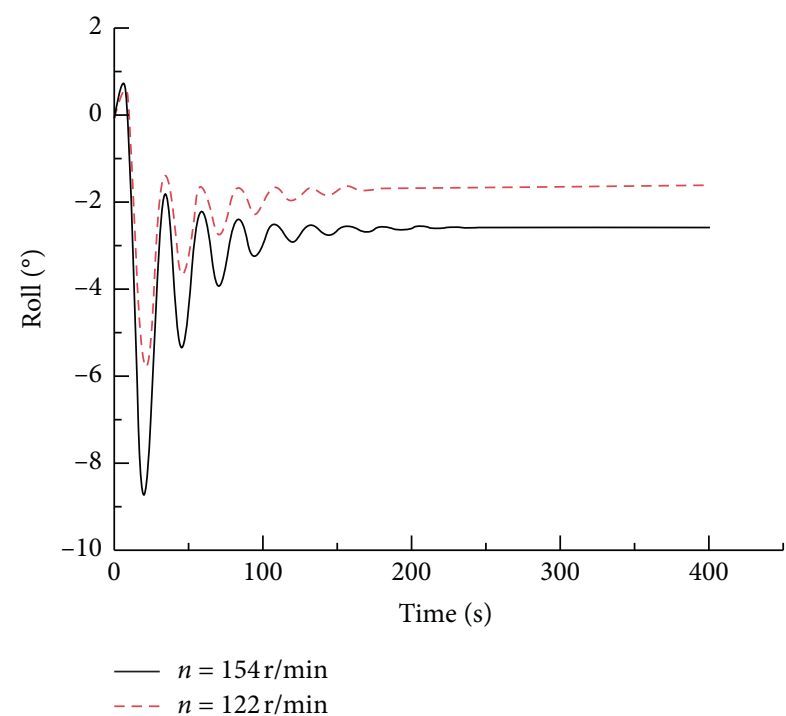

FIGURE 8: Roll angle for the ship's starboard side at different main engine speeds.

(3) According to the calculation book of the loading condition of the selected ship, when the main engine speed was 154 and $122 \mathrm{r} / \mathrm{min}$, the steady rotary roll angle of the ship was $2.6^{\circ}$ and $1.8^{\circ}$, respectively. As indicated by the curve of the roll angle, the simulation results fit well. Therefore, the mathematical model of manoeuvring movement developed in this study is reasonable.

4.2. Rotation at Different Rudder Angles. The initial speed of the ship was set as $32 \mathrm{~km} / \mathrm{h}$, with starboard roll angles of $10^{\circ}$, $20^{\circ}$, and $35^{\circ}$. To simulate the roll motion at different rudder angles of the ship in still water, the ship's roll trajectory was examined, as shown in Figure 9. The roll angle change curve is presented in Figure 10.

As indicated by the ship's roll trajectory, the ship's roll diameter was $2172.9 \mathrm{~m}$ at the steering angle of $10^{\circ}, 990.8 \mathrm{~m}$ at the rudder angle of $20^{\circ}$, and $487.8 \mathrm{~m}$ at the rudder angle of $35^{\circ}$. With the increasing rudder angle, the ship's gyration in still water decreased gradually, and the ship exhibited good gyration when sailing with a large rudder angle.

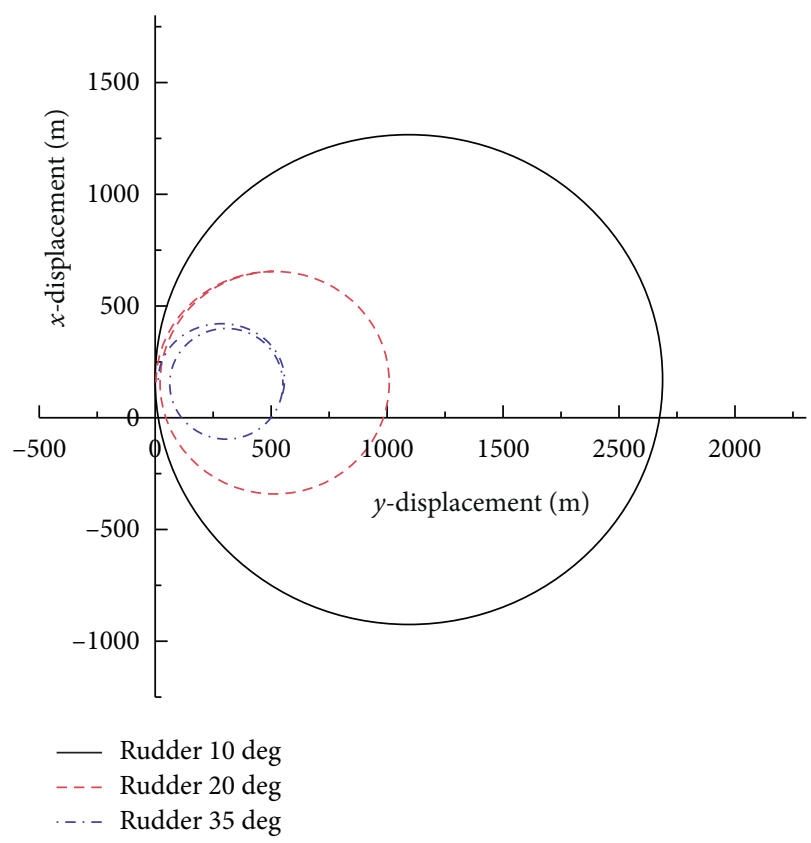

Figure 9: Ship roll tracks for different rudder angles.

From the analysis of the ship at different rudder angles, the transverse variation curve was obtained.

(1) With the increasing rudder angle, the time taken for the ship's roll angle to stabilise increased. When the ship sailed with a larger rudder angle, it needed to go through more rolls to reach the stable roll angle, whereas when the ship sailed with a smaller rudder angle, it entered the steady turning stage earlier.

(2) In the roll transition stage, the maximum dynamic roll angle of the ship was $2.34^{\circ}, 5.24^{\circ}$, and $8.75^{\circ}$ when the rudder angle was $10^{\circ}, 20^{\circ}$, and $35^{\circ}$, respectively. As the rudder angle increased, the maximum dynamic roll angle of the ship increased. Therefore, when the ship turned in static water, the rotary roll angle increased with the rudder angle. When the rudder angle increased to $20^{\circ}$, the rotary stable phase of the roll angle is no longer a significant change, always maintain relatively stable. 


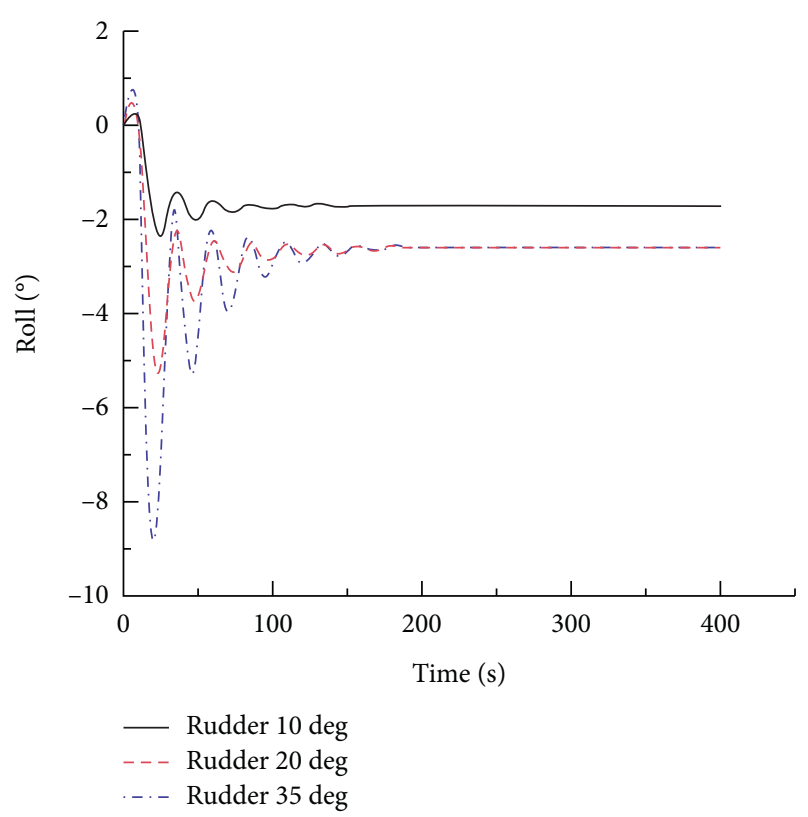

FIGURE 10: Ship's transverse change curves for different rudder angles.

\section{Analysis of Ship Roll Characteristics in Landslide-Generated Tsunamis}

The water entry point of the landslide body is mostly located on both sides of the channel, and the heeling moment is the largest and the risk is the highest when the transverse wave occurs. Therefore, in this study, the wave direction of the landslide-generated tsunamis is selected to be $90^{\circ}$; that is, the ship suffers from the action of the right transverse wave at the initial moment. The coupling action between the landslide surge and the ship is shown in Figure 11.

The working conditions and wave-height test results for the landslide example are presented in Table 4.

The landslide-genertated wave was highly nonlinear. Through the model test results, they show the landslidegenertated wave as stokes wave, elliptical cosine wave, solitary wave superposition; therefore, in this paper, the wave forces acting on the ideal landslide-genertated wave into irregular wave second-order drift force by the rules of formula of irregular wave spectrum and wave interference formula to calculate.

\subsection{Maximum Roll Angle at Different Sailing Positions.} To study the rolling situation of the ship at different direct sailing positions, five groups of repeated tests should be conducted when the ship is sailing. The first group involves the measurement of the ship's speed in still water, the second group involves the measurement of the time taken for the ship to sail to a fixed monitoring point, the third group involves the verification of the ship's passage position, and the fourth and fifth groups involve the extraction of test data. If there is a $5 \%$ difference between the results of the fourth and fifth groups, the next group of tests is conducted. If the error value of the two groups is $<5 \%$, the average value of the two groups is

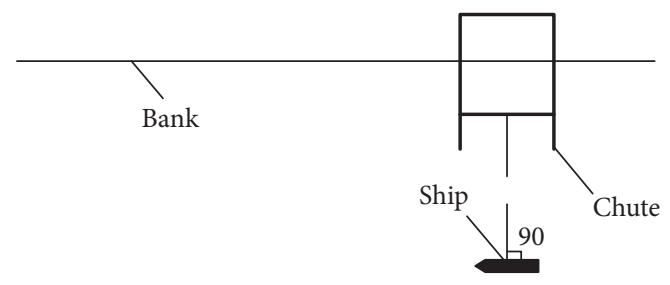

FIgURE 11: Schematic of the landslide surge and ship action.

taken as the test result. The ship sails in a straight line at the selected position with an initial speed of $26 \mathrm{~km} / \mathrm{h}$. The maximum wave height plot for different locations is shown in Figure 12, and the maximum roll angle calculations for different locations are presented in Figure 13.

As indicated by the analysis results in Figures 12 and 13, the height of landslide-generated tsunamis decreased sharply at a position close to the water entry point. With an increase in the distance from the water entry point, the maximum wave height of the surge gradually decreased, and the energy carried by the surge was continuously consumed. The maximum roll angle is an important index for the safety of ships sailing in waves. The International Maritime Organization stipulates that the limit roll angle of ships sailing safely in waves is $40^{\circ}$. When the roll angle is $>40^{\circ}$, the stability characteristics of ships change, which can lead to disasters. To prevent cargo movement and waves on deck, the water inlet angle and the maximum dynamic inclination angle of the ship should be considered. The minimum values of the three should be taken as the standard to measure the safety of the ship. The engineering experience value is $15^{\circ}$; that is, the limit roll angle for the ship's safe navigation is $15^{\circ}$.

According to the regulations of the International Maritime Organization, the maximum safe roll angle for straight sailing in the wind and waves is $15^{\circ}$; that is, when the roll angle exceeds $15^{\circ}$, the ship is in considerable danger of capsizing. As shown in Figure 13, the maximum roll angle of the ship reaches $21.74^{\circ}, 16.30^{\circ}$, and $15.62^{\circ}$ at 100,200 , and $280 \mathrm{~m}$, respectively, when the ship is prone to capsizing. When the ship is 400 and $500 \mathrm{~m}$ from the landslide entry point, the maximum roll angle is $8.98^{\circ}$ and $7.64^{\circ}$, respectively (both less than $15^{\circ}$ ); thus, the ship is relatively safe to navigate. In order to guarantee safety of ship by the form of traffic control, appropriate to allow ships can drift along in the appropriate scope, away from the landslide area decreased risk capsizing. Through considerable manoeuvring motion analysis, the relationship between the wave height and the maximum roll angle was determined, as shown in Table 5.

When the ship sails at an initial speed of $26 \mathrm{~km} / \mathrm{h}$ and the distance from the landslide entry point is $>400 \mathrm{~m}$, the area is relatively safe. At this time, the ship is safe during the navigation. According to the results of this study, for sailing to be safe, the ship should be $400-560 \mathrm{~m}$ from the landslide entry point under this condition. 
TABLe 4: Properties of landslide-generated tsunamis.

Depth $(\mathrm{m})$ 75.5

Actual landslide volume $\left(\mathrm{m}^{3}\right)$

Landslide angle $\left({ }^{\circ}\right)$

Slope width of landslide section (m)

Distance between model and water entry point $(\mathrm{m})$

Distance between original model and water entry point (m)

Maximum wave height of model surge $(\mathrm{cm})$

Maximum wave height of original model surge $(\mathrm{m})$

\begin{tabular}{cccccc} 
& \multicolumn{5}{c}{75.5} \\
& & \multicolumn{5}{c}{$1.03 \times 10^{5}$} \\
& & $40^{\circ}$ & & \\
& & 560 & & \\
& 1.43 & 2.86 & 4.00 & 5.71 & 7.14 \\
& 100 & 200 & 280 & 400 & 500 \\
& 7.284 & 5.026 & 4.591 & 3.829 & 3.142 \\
& 5.099 & 3.518 & 3.214 & 2.680 & 2.199 \\
\hline
\end{tabular}

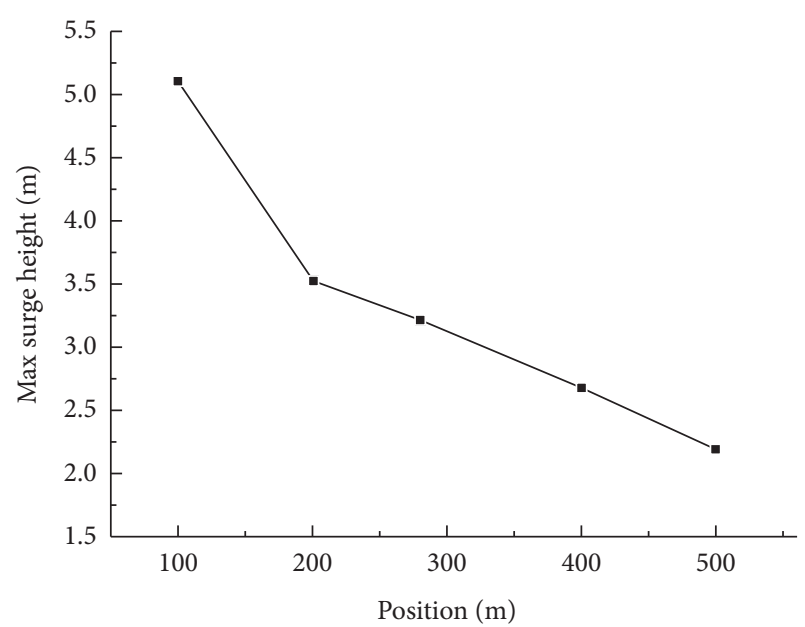

Figure 12: Maximum wave height of surges at different locations.

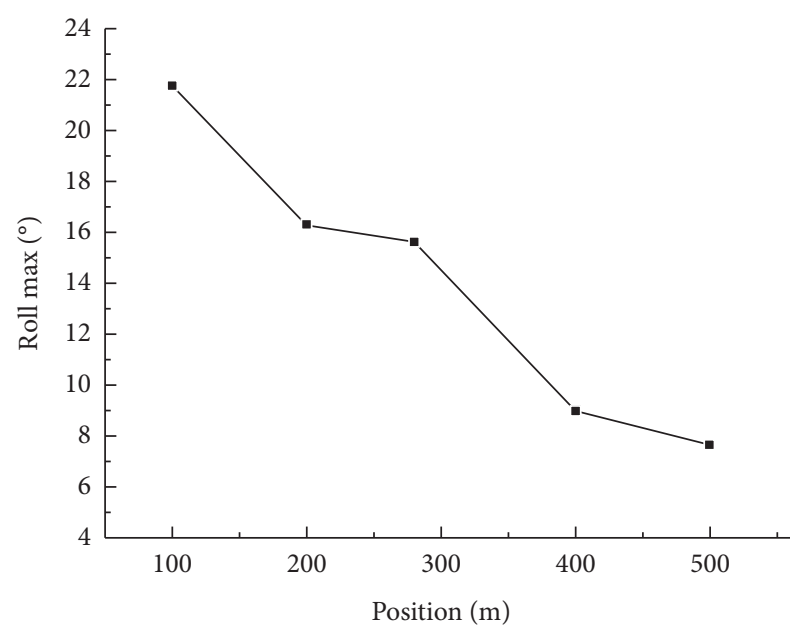

FIgUre 13: Maximum roll angle of a ship at different locations.

5.2. Maximum Roll Angle at Different Speeds. To study the maximum roll angle of the ship at different speeds, the propeller propulsion speed was controlled by changing the rotating speed of the main engine, and the average speed of this section was taken as the monitoring speed for fixed-distance navigation monitoring. Initial speeds of 15,18 , and $21 \mathrm{~km} / \mathrm{h}$ were selected. Due to ship is located at $100 \mathrm{~m}$ and $200 \mathrm{~m}$, and $280 \mathrm{~m}$, the maximum roll angle is more than maximum security heeling angle, this period belongs to the dangerous area; therefore, this section of the ship in the 400 and $500 \mathrm{~m}$ from landslides in a relatively safe location, as shown in Figure 14.
TABLE 5: Relationship between the wave height and the maximum roll angle.

\begin{tabular}{lccc}
\hline $\begin{array}{l}\text { Wave height } \\
(\mathrm{m})\end{array}$ & $\begin{array}{c}\text { Location } \\
(\mathrm{m})\end{array}$ & $\begin{array}{c}\text { Maximum ship roll angle } \\
\left({ }^{\circ}\right)\end{array}$ & Safety \\
\hline 5.099 & 100 & 21.74 & Unsafe \\
3.518 & 200 & 16.30 & Unsafe \\
3.214 & 280 & 15.62 & Unsafe \\
2.680 & 400 & 8.98 & Safe \\
2.199 & 500 & 7.64 & Safe \\
\hline
\end{tabular}

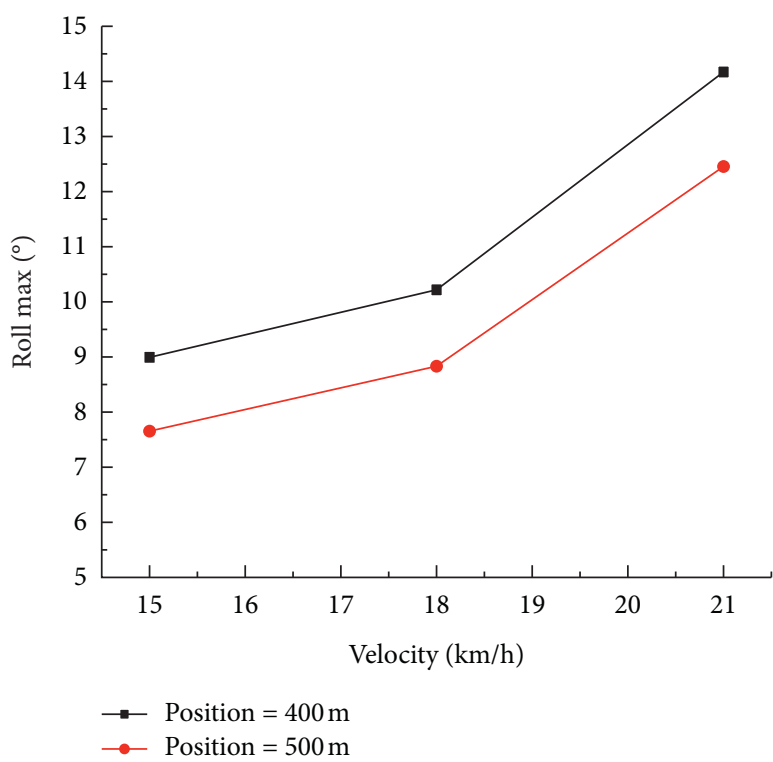

Figure 14: Maximum roll angle at different speeds.

As shown in Figure 14, when the ship was $500 \mathrm{~m}$ from the landslide entry point, the maximum roll angle of the ship at all speeds was smaller than the roll angle at $400 \mathrm{~m}$; that is, the maximum roll angle of the ship decreased gradually with the increasing distance from the landslide entry point. The largest value of the maximum roll angle was $14.16^{\circ}$ from the water entry point of the landslide to $400 \mathrm{~m}$, which occurred at the maximum speed. Under this working condition, the ship's roll angle was close to the ultimate roll angle of $15^{\circ}$, which was a dangerous working condition; that is, the wave height was $2.68 \mathrm{~m}$, and the sailing speed was $38 \mathrm{~km} / \mathrm{h}$. The minimum roll angle was $8.98^{\circ}$, which occurred at the lowest speed. When the ship was $500 \mathrm{~m}$ from the landslide entry point, its maximum roll angle was $12.44^{\circ}$ at a speed of $38 \mathrm{~km} / \mathrm{h}$ and $7.64^{\circ}$ at a 
speed of $26 \mathrm{~km} / \mathrm{h}$. As shown in Figure 14, when the distance from the landslide entry point was fixed, the ship's maximum roll angle gradually increased with the speed. The maximum roll angle of the ship did not exceed $15^{\circ}$ in any of the working conditions. Therefore, when the ship sails in the area of $400-500 \mathrm{~m}, 26-38 \mathrm{~km} / \mathrm{h}$ is a safe speed range that does not present a danger of capsizing. The relationship between the ship's initial speed and the maximum roll angle is presented in Table 6.

In summary, in the process of ship navigation, the ship's speed is too fast, resulting in a large roll angle, which can easily cause the hull to overturn; thus, the pilot should fully consider the state of the ship according to the actual situation to weigh the advantages and disadvantages of the choice.

\subsection{Maximum Roll Angle at Different Rudder Angles.} Steering angles of $10^{\circ}, 15^{\circ}, 20^{\circ}, 25^{\circ}$, and $35^{\circ}$ were selected, and the ship sailed at relatively safe positions of the $400 \mathrm{~m}$ and $500 \mathrm{~m}$ landslide water inlet points, at initial speeds of 26, 32, and $38 \mathrm{~km} / \mathrm{h}$. The maximum roll angle was recorded, as shown in Figures 15 and 16.

As shown in Figures 15 and 16, the maximum roll angle for each rudder angle always increased with the speed. For ships under the action of landslide-generated tsunamis, when the initial speed was constant, the maximum roll angle increased with the rudder angle. As shown in Figure 15, when the ship's sailing speed was $26 \mathrm{~km} / \mathrm{h}$, the ship's sailing rudder angle was $15^{\circ}$, and the ship's maximum rolling angle was $12.45^{\circ}$. When the ship's sailing speed was $32 \mathrm{~km} / \mathrm{h}$, the ship's sailing rudder angle was $10^{\circ}$, and the ship's maximum rolling angle was $13.21^{\circ}$. When the ship's sailing speed was $26 \mathrm{~km} / \mathrm{h}$, the ship's sailing rudder angle was $15^{\circ}$, and the ship's maximum rolling angle was $12.45^{\circ}$. When the ship's sailing speed was $38 \mathrm{~km} / \mathrm{h}$, the ship's rudder angle was $10^{\circ}$, the ship's maximum roll angle was $17.69^{\circ}$, and the ship's navigation was in an unsafe state.

As shown in Figure 16, when the ship's sailing speed was $26 \mathrm{~km} / \mathrm{h}$, the ship's sailing rudder angle was $20^{\circ}$, and the ship's maximum rolling angle was $13.64^{\circ}$. When the ship's sailing speed was $38 \mathrm{~km} / \mathrm{h}$, the ship's rudder angle was $10^{\circ}$, the ship's maximum roll angle was $14.43^{\circ}, 15^{\circ}$, and $18.12^{\circ}$, and the ship's navigation was in an unsafe state. The relationship between the steering angle and the roll angle is presented in Tables 7-9.

As shown in Figures 15 and 16, the maximum roll angle for each rudder angle always increased with the speed. As indicated by Tables 7-9, for ships under the action of landslide-generated tsunamis, when the initial speed was constant, the maximum roll angle increased sharply with the steering. A larger rudder angle corresponded to a higher risk of capsizing. Therefore, it is inappropriate to conduct largerudder angle steering in surges and even less appropriate to conduct emergency steering. With the increasing distance from the water entry point of the landslide, the range of the steering angle of the ship increased, but the safe steering angle remained small $\left(<20^{\circ}\right)$. When the ship is far from the water entry point of the landslide, a small rudder angle can be used to ensure the navigation safety, after the state of the ship and the wind and wave conditions are confirmed.

\section{Ship Track Analysis in Landslide- Generated Tsunamis}

To analyse the ship-shore collision risk, one should first ensure that the vessels under landslide-generated tsunamis is not happened beforehand; therefore, to study the track conditions of ship in the landslide-generated tsunamis, the largest rolling of ship is the basis of the analysis results, selection of navigation position, the initial speed and steering rudder angle are no overturning danger relative safety conditions, the simulation are in the initial wave to transverse wave under the condition of specific conditions, as shown in Table 10.

6.1. Ship's Navigation Trajectory at Zero Rudder Angle. Working conditions 1-3 and 4-6 were selected to study the ship's motion trajectory during steering from the water entry point of the landslide to distances of 400 and $500 \mathrm{~m}$, respectively, as shown in Figures 17 and 18.

As shown in Figures 17 and 18, under the action of landslide-generated tsunamis, the ship did not conduct steering. Additionally, the ship's trajectory gradually shifted from the initial straight course to the direction of wave propagation, and the deviation became increasingly obvious. This is because the wave direction angle changed during the process of movement. An abscissa diagram indicated the ship motion offsets and the variation of the vertical displacement for the ship sailing direction. At the beginning, the ship was only affected by the transverse wave, and the transverse oscillation amplitude change of the vessel was partly a result of the landslide surge on the main body and partly due to the landslide surge over the surface of the rudder, which caused the turning of the rudder and made the ship deviate significantly from the initial position.

The ship was eventually affected by the component force in the wave direction. When the landslide-generated tsunamis disappear, if no steering is performed, the ship will sail in a straight line along the deflected heading direction; thus, the ship will eventually be far from the original course and collide with the shore wall. When the distance from the water entry point of the landslide was fixed, the ship's movement trajectories at different sailing speeds were analysed and compared. A higher initial sailing speed yielded a greater track offset of the ship under the action of landslide-generated tsunamis. Therefore, to maintain good course stability, the speed of the ship should be appropriately reduced in a landslide-generated tsunami. At a given speed, ship trajectories at different positions were analysed comparatively. With an increase in the distance from the water entry point of the landslide, the wave declined, and the force on the ship decreased. Additionally, the offset along the $Y$ axis caused by the landslide-generated tsunamis in the ship's trajectory decreased significantly. 
TABLE 6: Relationship between the initial speed and the maximum roll angle.

\begin{tabular}{lccc}
\hline Wave height $(\mathrm{m})$ & Initial speed $(\mathrm{km} / \mathrm{h})$ & Maximum ship roll angle $\left(^{\circ}\right)$ & Safety \\
\hline \multirow{2}{*}{2.680} & 26 & 8.98 & Safe \\
& 32 & 10.21 & Safe \\
\hline \multirow{2}{*}{2.199} & 38 & 14.16 & Unsafe \\
& 26 & 7.64 & Safe \\
& 32 & 12.83 & Safe \\
Safe \\
\hline
\end{tabular}

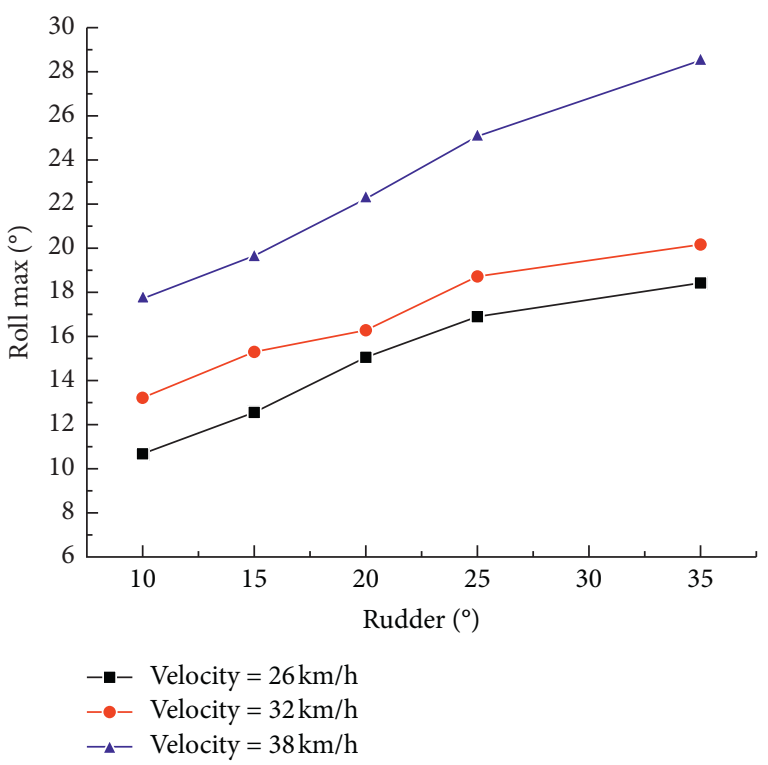

FIGURE 15: Maximum roll angle at $400 \mathrm{~m}$ with respect to the rudder angle.

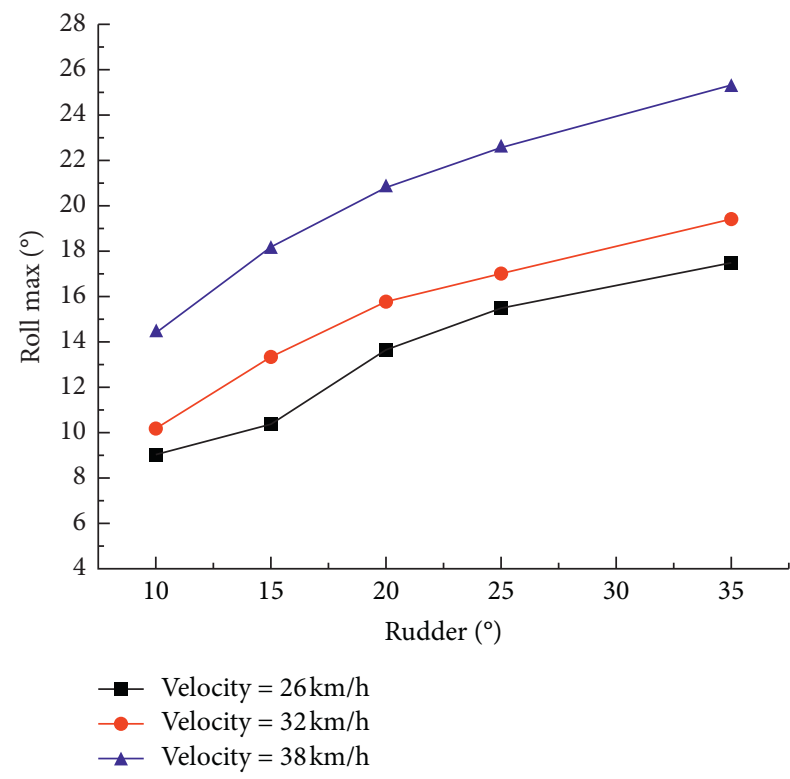

FIGURE 16: Maximum roll angle at $500 \mathrm{~m}$ with respect to the rudder angle.
TABLE 7: Relationship between the steering angle and the maximum roll angle at the initial speed of $26 \mathrm{~km} / \mathrm{h}$.

\begin{tabular}{lccc}
\hline $\begin{array}{l}\text { Wave height } \\
(\mathrm{m})\end{array}$ & $\begin{array}{c}\text { Rudder angle } \\
\left({ }^{\circ}\right)\end{array}$ & $\begin{array}{c}\text { Maximum ship roll } \\
\text { angle }\left(^{\circ}\right)\end{array}$ & Safety \\
\hline & 10 & 10.64 & Safe \\
& 15 & 12.45 & Safe \\
2.680 & 20 & 15.09 & Unsafe \\
& 25 & 16.94 & Unsafe \\
& 35 & 18.43 & Unsafe \\
\hline & 10 & 9.04 & Safe \\
& 15 & 10.37 & Safe \\
& 20 & 13.64 & Safe \\
& 25 & 15.52 & Unsafe \\
& 35 & 17.48 & Unsafe \\
\hline
\end{tabular}

TABLE 8: Relationship between the steering angle and the maximum roll angle at the initial speed of $32 \mathrm{~km} / \mathrm{h}$.

\begin{tabular}{lccc}
\hline $\begin{array}{l}\text { Wave height } \\
(\mathrm{m})\end{array}$ & $\begin{array}{c}\text { Rudder angle } \\
\left({ }^{\circ}\right)\end{array}$ & $\begin{array}{c}\text { Maximum ship roll } \\
\text { angle }\left({ }^{\circ}\right)\end{array}$ & Safety \\
\hline & 10 & 13.21 & Safe \\
2.680 & 15 & 15.34 & Unsafe \\
& 20 & 16.32 & Unsafe \\
& 25 & 18.73 & Unsafe \\
& 35 & 20.17 & Unsafe \\
\hline \multirow{3}{*}{199} & 10 & 10.22 & Safe \\
& 15 & 13.36 & Safe \\
& 20 & 15.79 & Unsafe \\
& 25 & 17.06 & Unsafe \\
& 35 & 19.45 & Unsafe \\
\hline
\end{tabular}

TABLE 9: Relationship between the steering angle and the maximum roll angle at the initial speed of $38 \mathrm{~km} / \mathrm{h}$.

\begin{tabular}{lccc}
\hline $\begin{array}{l}\text { Wave height } \\
(\mathrm{m})\end{array}$ & $\begin{array}{c}\text { Ruder angle } \\
\left({ }^{\circ}\right)\end{array}$ & $\begin{array}{c}\text { Maximum ship roll angle } \\
\left({ }^{\circ}\right)\end{array}$ & Safety \\
\hline & 10 & 17.69 & Unsafe \\
& 15 & 19.62 & Unsafe \\
2.680 & 20 & 22.26 & Unsafe \\
& 25 & 25.11 & Unsafe \\
& 35 & 28.5 & Unsafe \\
\hline & 10 & 14.43 & Safe \\
2.199 & 15 & 18.12 & Unsafe \\
& 20 & 20.84 & Unsafe \\
& 25 & 22.55 & Unsafe \\
& 35 & 25.29 & Unsafe \\
\hline
\end{tabular}


TABLE 10: Ship track forecast operating conditions.

\begin{tabular}{lccc}
\hline Case & Distance $(\mathrm{m})$ & Speed $(\mathrm{km} / \mathrm{h})$ & Rudder angle $\left(^{\circ}\right)$ \\
\hline$\# 1$ & 400 & 26 & $<15^{\circ}$ \\
$\# 2$ & 400 & 32 & $<10^{\circ}$ \\
$\# 3$ & 400 & 38 & - \\
$\# 4$ & 500 & 26 & $<20^{\circ}$ \\
$\# 5$ & 500 & 32 & $<15^{\circ}$ \\
$\# 6$ & 500 & 38 & $<10^{\circ}$ \\
\hline
\end{tabular}

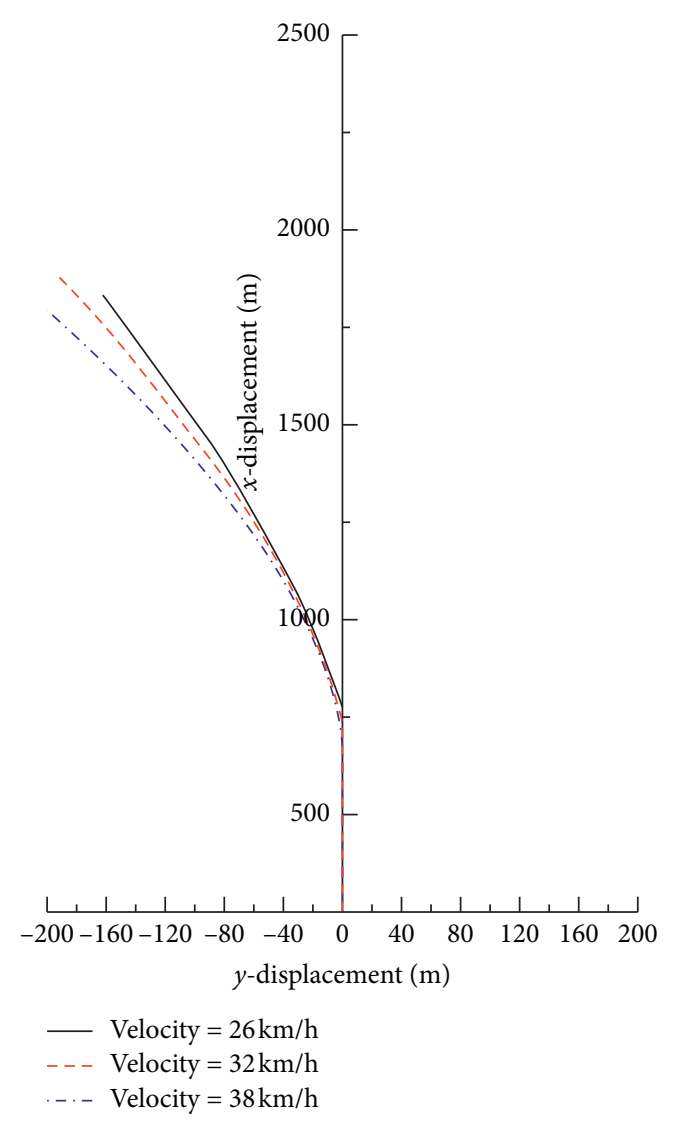

FIGURE 17: Ship's trajectory without steering at $400 \mathrm{~m}$.

6.2. Ship's Navigation Trajectory during Steering. The ship encountered landslide-generated tsunamis during sailing, and the ship's track gradually deviated without steering. The width of the river course in the landslide area selected in this study was $560 \mathrm{~m}$. As the ship continued to sail, its offset in the $Y$ direction at 400 and $500 \mathrm{~m}$ exceeded 160 and $60 \mathrm{~m}$, respectively; that is, the ship hit the bank slope, and a collision occurred. Therefore, to avoid ship collision accidents and ensure the safety of the ship navigation, steering should be performed in advance.

To ensure the navigation safety of the ship, it was assumed that the ship started steering after sailing $100 \mathrm{~m}$ under the action of landslide-generated tsunamis, and the ship's track at the limit rudder angle was predicted under each working condition.

When the ship's initial speed reached $38 \mathrm{~km} / \mathrm{h}$ at the position $400 \mathrm{~m}$ from the landslide entry point, the ship was easily capsized with the rudder, whereas a ship-shore

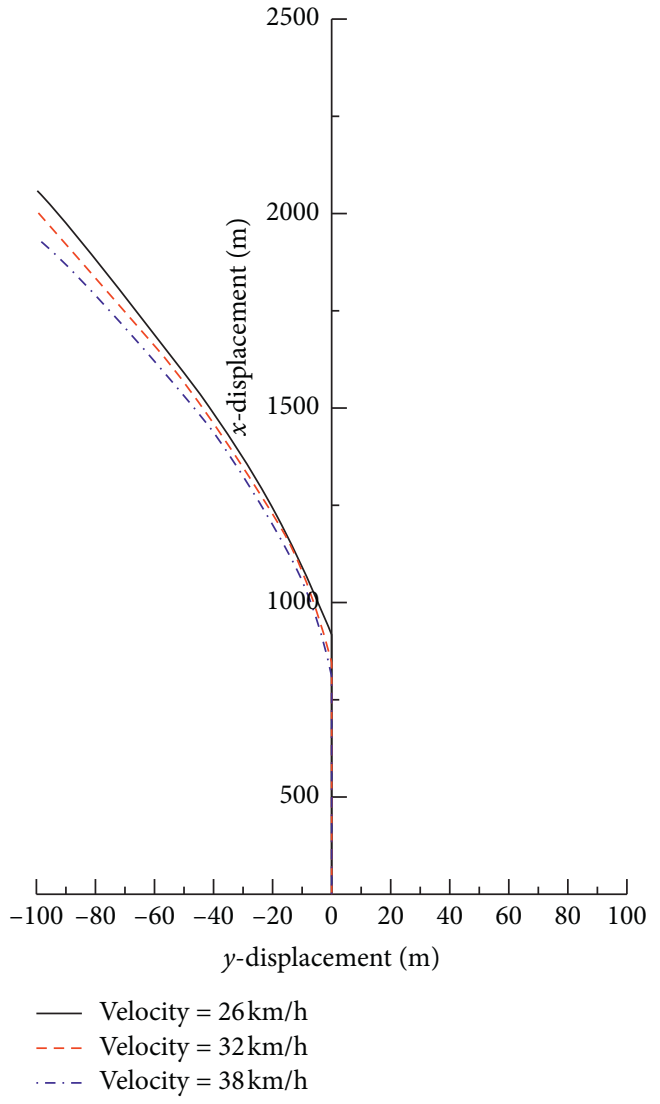

FIgURE 18: Ship's trajectory without steering at $500 \mathrm{~m}$.

collision occurred without the rudder. Therefore, in the calculation example, a ship with a speed of $38 \mathrm{~km} / \mathrm{h}$ cannot sail safely with a rudder; thus, it is in a dangerous sailing state. When the initial sailing speed is $26 \mathrm{~km} / \mathrm{h}$, the ultimate safe rudder angle is selected to be $15^{\circ}$, and the safe rudder angle is selected to be $10^{\circ}$ when the sailing speed is $32 \mathrm{~km} / \mathrm{h}$. The ship movement trajectories in the two foregoing conditions (working conditions 1 and 2) were simulated. The results are presented in Figures 19 and 20.

As shown in Figures 19 and 20, before the steering, the ship's sailing path was shifted in the direction of landslidegenerated tsunami propagation. When the ship started steering, it moved in the direction of migration for a certain distance, but the track offset increased, and the ship slowed until the maximum offset was reached.

When the speed was $26 \mathrm{~km} / \mathrm{h}$ and the ultimate safety rudder angle was $15^{\circ}$, the maximum lateral offset of the ship's trajectory was $53.3 \mathrm{~m}$, which is significantly smaller than 


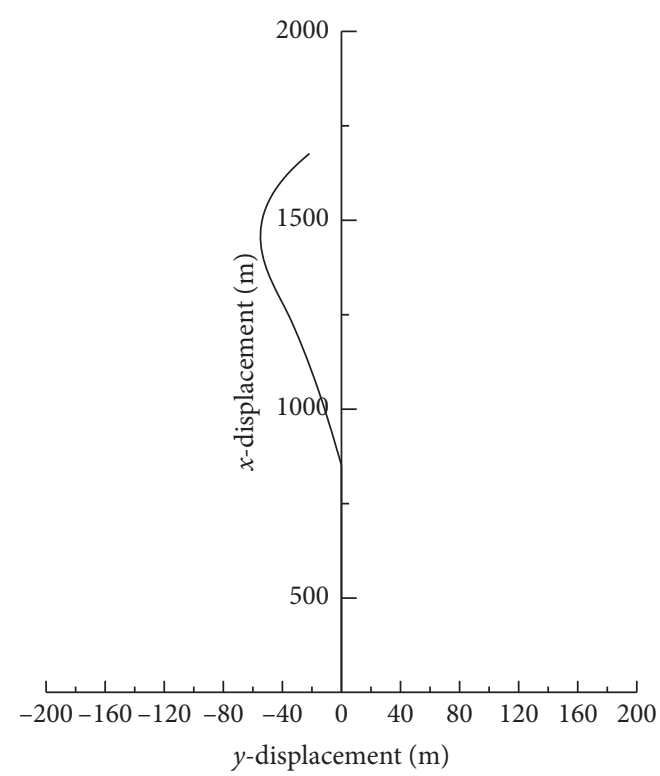

FIGURE 19: Trajectory for a rudder angle of $15^{\circ}$ and a ship speed of $26 \mathrm{~km} / \mathrm{h}$.

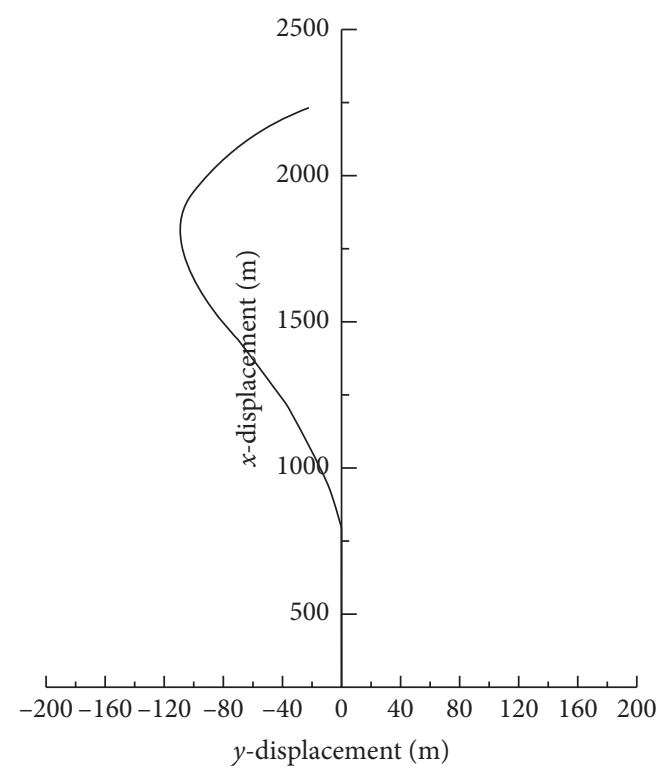

FIgURE 20: Trajectory for a rudder angle of $10^{\circ}$ and a ship speed of $32 \mathrm{~km} / \mathrm{h}$.

$160 \mathrm{~m}$. Thus, the ship could avoid a collision with the bank slope by turning the rudder without capsizing. When the speed was $32 \mathrm{~km} / \mathrm{h}$ and the ultimate safety rudder angle was $10^{\circ}$, the maximum lateral offset of the ship's trajectory was $108.1 \mathrm{~m}$, which is smaller than $160 \mathrm{~m}$. At this time, the ship could still avoid a collision with the bank slope.

For the position $500 \mathrm{~m}$ from the water inlet point of the landslide, the ship's movement trajectory under working conditions 4-6 was simulated, and the influence of the steering angle was considered. The results are shown in Figure 21.

As shown in Figure 21, the maximum track lateral offset was $30.4 \mathrm{~m}$ for condition $4,56.4 \mathrm{~m}$ for condition 5 , and

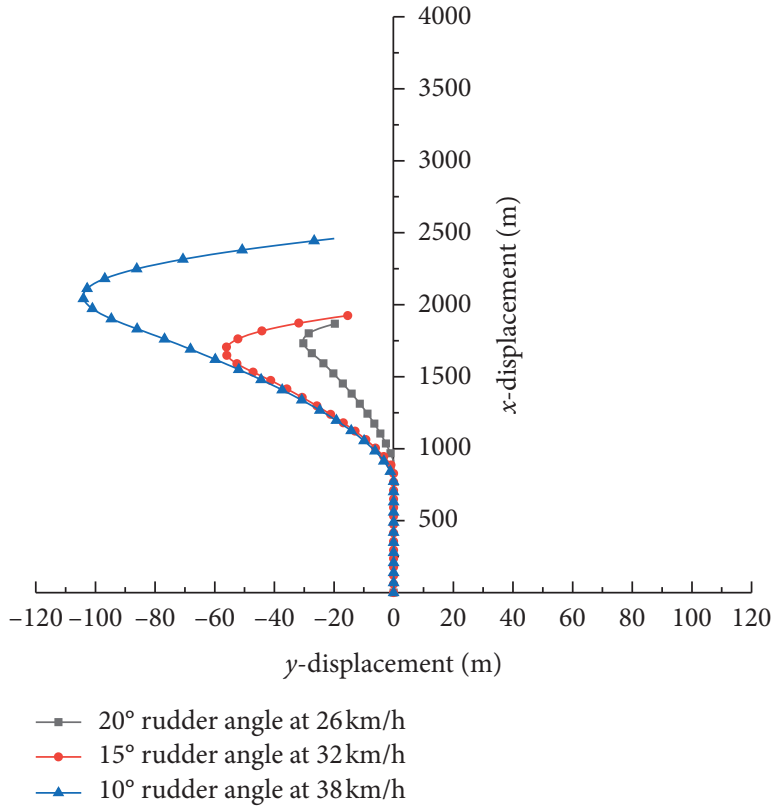

FIgURE 21: Trajectory of the ship at different speeds and rudder angles.

$104.1 \mathrm{~m}$ for condition 6 . To avoid the collision between the ship and the bank slope, the maximum offset should be $<60 \mathrm{~m}$ at this time. Thus, working conditions 4 and 5 satisfied the requirements, whereas working condition 6 did not.

In summary, according to the example of the cruise ship of Yangtze river in the Three Gorges Reservoir area sailing in the Tuokou area of Yiwan Yangtze river bridge, to ensure the navigation safety of the ship, it should sail at a distance of 400-500 $\mathrm{m}$ from the water point of the landslide. When course deviation occurs, a ship-shore collision can be avoided via proper steering, and the ship can return to the initial route. At a distance of $400 \mathrm{~m}$, when the initial sailing speed was $26 \mathrm{~km} / \mathrm{h}$, the ship steering angle was $15^{\circ}$, and when the initial sailing speed was $32 \mathrm{~km} / \mathrm{h}$, the ship steering angle was $10^{\circ}$ for ensuring the navigation safety of the ship. In these two cases, the maximum roll angle was $12.45^{\circ}$ and $13.21^{\circ}$, respectively, and the maximum yaw distance was 53.3 and $108.1 \mathrm{~m}$, respectively. At a distance of $500 \mathrm{~m}$, a steering angle of $20^{\circ}$ at a speed of $26 \mathrm{~km} / \mathrm{h}$ ensured the navigation safety of the ship. In this case, the maximum roll angle was $13.64^{\circ}$, and the maximum yaw distance was $30.4 \mathrm{~m}$ the speed of the ship at $26 \mathrm{~km} / \mathrm{h}$, and the steering is $20^{\circ}$ to ensure the safety of the ship's navigation.

\section{Conclusions}

The geological environment of the Three Gorges Reservoir is complex and prone to landslides. The falling of the landslide body into the water results in landslide-generated tsunamis with a large amount of energy, which pose a considerable threat to the navigation safety of ships. Therefore, it is of practical significance to investigate the ship's handling characteristics in landslide-generated tsunamis. In this study, according to the empirical formula method, a 
mathematical model of four-degree-of-freedom ship manoeuvring movement was established, and the maximum roll angle and ship track line changes in static water and landslide-generated tsunamis were investigated through the established simulation program. According to the results, the following conclusions are drawn.

(1) At a shorter distance to the water inlet, landslidegenerated tsunamis are higher, the ship's roll angle is larger, and navigation is more dangerous for larger ships. Therefore, the ship sailing in the range of conditions permit, in case of sudden landslide-generated tsunamis, according to ship the location, quickly away from the area. The ship should avoid a large rudder angle, particularly the emergency steering.

(2) If no steering is performed in landslide-generated tsunamis, the ship's trajectory gradually shifts from the initial straight course to the propagation direction of the landslide-generated tsunami. In the same external environment, a higher initial speed results in a larger horizontal deviation distance of the ship. When the ship starts to steer, the increase in the ship's outward migration slows, and after the maximum offset is reached, the direction of the track line can be restored under the action of the rudder force.

(3) The developed simulation program for ship control movement can be used to study the effects of landslide-generated tsunamis on the ship control characteristics. The examples selected in this study were rudder angles of $15^{\circ}, 10^{\circ}$, and $20^{\circ}$ at initial ship speeds of 26,32 , and $26 \mathrm{~km} / \mathrm{h}$, respectively, from the landslide point of $400 \mathrm{~m}$. These conditions are recommended for safe navigation of the ship.

\section{Data Availability}

The data used to support the findings of this study are available from the corresponding author upon request.

\section{Conflicts of Interest}

The authors declare that there are no conflicts of interest regarding the publication of this paper.

\section{Acknowledgments}

This study was financially supported by the National Natural Science Foundation of China (51479015), the Social Science and Technology Innovation Program for People's Livelihood in Chongqing (cstc2019ngzx0017, cstc2019jscx-msxmX0302, cstc2018jscx-msybX0233, and cstc2019jscx-lyjsAX0008), and the Science and Technology Program of Chongqing Education Commission (KJQN201900735).

\section{References}

[1] H. M. Fritz, Initial phase of landslide generated impulse waves, Ph.D. thesis, Eidgenössische Technischen Hochschule Zürich, Zürich, Switzerland, 2002.
[2] J. S. Walder, P. Watts, O. E. Sorensen, and K. Janssen, "Tsunamis generated by subaerial mass flows," Journal of Geophysical Research, vol. 108, p. 2236, 2003.

[3] A. Panizzo, P. De Girolamo, and A. Petaccia, "Forecasting impulse waves generated by subaerial landslides," Journal of Geophysical Research, vol. 110, 2005.

[4] M. Di Risio, G. Bellotti, A. Panizzo, and P. De Girolamo, "Three-dimensional experiments on landslide generated waves at a sloping coast," Coastal Engineering, vol. 56, no. 5-6, pp. 659-671, 2009.

[5] V. Heller, M. Moalemi, R. D. Kinnear, and R. A. Adams, "Geometrical effects on landslide-generated tsunamis," Journal of Waterway, Port, Coastal, and Ocean Engineering, vol. 138, no. 4, pp. 286-298, 2012.

[6] M. Bruggemann, "Composite modelling of the influence of geometry on landslide generated impulse waves," in Proceedings of the 1st Civil and Environmental Engineering Student Conference, Imperial College London, London, UK, June 2012.

[7] V. Heller and J. Spinneken, "On the effect of the water body geometry on landslide-tsunamis: physical insight from laboratory tests and 2D to 3D wave parameter transformation," Coastal Engineering, vol. 104, no. 10, pp. 113-134, 2015.

[8] S. Yavari-Ramshe and B. Ataie-Ashtiani, "A rigorous finite volume model to simulate subaerial and submarine landslidegenerated waves," Landslides, vol. 14, no. 1, pp. 203-221, 2017.

[9] B. Ataie-Ashtiani and S. Yavari-Ramshe, "Numerical simulation of wave generated by landslide incidents in dam reservoirs," Landslides, vol. 8, no. 4, pp. 417-432, 2011.

[10] G. Ruffini, V. Heller, and R. Briganti, "Numerical modelling of landslide-tsunami propagation in a wide range of idealized water body geometries," Coastal Engineering, vol. 153, Article ID 103518, 2019.

[11] K. Kelfoun, T. Glachetti, and P. Labazuy, "landslide-generated tsunamis at reunion island," Journal of Geophysical ResearchEarth Surface, vol. 115, 2010.

[12] A. Farhadi, "ISPH numerical simulation of tsunami generation by submarine landslides," Arabian Journal of Geosciences, vol. 11, no. 12, 2018.

[13] C. Cecioni and G. Bellotti, "Modeling tsunamis generated by submerged landslides using depth integrated equations," Applied Ocean Research, vol. 32, no. 3, pp. 343-350, 2010.

[14] S. E. Hirdaris, W. Bai, D. Dessi et al., "Loads for use in the design of ships and offshore structures," Ocean Engineering, vol. 78, pp. 131-174, 2014.

[15] K. Sasa, D. Terada, S. Shiotani et al., "A study of numerical simulation of ship motions while underway using a coastal wave database," International Journal of Offshore and Polar Engineering, vol. 22, no. 1, pp. 38-45, 2012.

[16] S. Kianejad, H. Enshaei, J. Duffy, and N. Ansarifard, "Calculation of ship roll hydrodynamic coefficients in regular beam waves," Ocean Engineering, vol. 203, Article ID 107225, 2020.

[17] V. Piscopo, A. Scamardella, and S. Gaglione, "A new wave spectrum resembling procedure based on ship motion analysis," Ocean Engineering, vol. 201, Article ID 107137, 2020.

[18] M.-G. Seo and Y. Kim, "Numerical analysis on ship maneuvering coupled with ship motion in waves," Ocean Engineering, vol. 38, no. 17-18, pp. 1934-1945, 2011.

[19] R. Szlapczynski, P. Krata, and J. Szlapczynska, "Ship domain applied to determining distances for collision avoidance manoeuvres in give-way situations," Ocean Engineering, vol. 165, pp. 43-54, 2018. 
[20] J.-H. Lee and Y. Kim, "Study on steady flow approximation in turning simulation of ship in waves," Ocean Engineering, vol. 195, Article ID 106645, 2020.

[21] P. Yuan, P. Wang, and Y. Zhao, "Model test research on the propagation of tsunamis and their interaction with navigating ships," Applied Sciences, vol. 9, no. 3, p. 475, 2019.

[22] P.-Y. Yuan, P.-Y. Wang, Y. Zhao, and M.-L. Wang, "Experimental study on the nonlinear behavior of a sailing container ship under landslide-induced surges," Advances in Civil Engineering, vol. 2019, Article ID 3240812, 10 pages, 2019.

[23] P. Heinrich, "Nonlinear water waves generated by submarine and aerial landslides," Journal of Waterway, Port, Coastal, and Ocean Engineering, vol. 118, no. 3, pp. 249-266, 1992. 